OPEN

SUBJECT AREAS:

CONSERVATION

ECOLOGY

Received

21 August 2013

Accepted

4 February 2014

Published

13 March 2014

Correspondence and requests for materials should be addressed to R.W. (rmcw@standrews.ac.uk)

* Current address: Marine Mammal Institute, Oregon State University, 2030 SE Marine Science Drive, Newport, OR 97365

\title{
Counting whales in a challenging, changing environment
}

\author{
R. Williams' ${ }^{1}$, N. Kelly ${ }^{2,3}$, O. Boebel ${ }^{4}$, A. S. Friedlaender ${ }^{*}$, H. Herr ${ }^{6}$, K.-H. Kock ${ }^{7}$, L. S. Lehnert ${ }^{6}$, T. Maksym ${ }^{8}$, \\ J. Roberts ${ }^{5}$, M. Scheidat ${ }^{9}$, U. Siebert ${ }^{6} \&$ A. S. Brierley ${ }^{10}$
}

\begin{abstract}
${ }^{1}$ Sea Mammal Research Unit, Scottish Oceans Institute, University of St Andrews, St Andrews KY 16 8LB, UK, ${ }^{2}$ CSIRO Computational Informatics and Wealth from Oceans Flagship, Hobart, Tasmania, 7000, Australia, ${ }^{3}$ Australian Marine Mammal Centre, Kingston, Tasmania, 7050, Australia, ${ }^{4}$ Alfred Wegener Institute, Bremerhaven, Germany, ${ }^{5}$ Marine Geospatial Ecology Lab, Duke University Marine Laboratory, Beaufort, NC 28516, USA, Institute for Terrestrial and Aquatic Wildlife Research, University of Veterinary Medicine Hannover, Foundation, Buesum, Germany, ${ }^{7} J o h a n n$ Heinrich von Thünen Institute, Institute of Sea Fisheries, Hamburg, Germany, ${ }^{8}$ Woods Hole Oceanographic Institution, Woods Hole, MA, 02543, USA, ${ }^{9}$ IMARES, Institute for Marine Resources and Ecosystem Studies, 1970 AB IJmuiden, The Netherlands, ${ }^{10}$ Pelagic Ecology Research Group, Scottish Oceans Institute, School of Biology, University of St Andrews, St Andrews, KY16 8LB, Scotland UK.
\end{abstract}

Estimating abundance of Antarctic minke whales is central to the International Whaling Commission's conservation and management work and understanding impacts of climate change on polar marine ecosystems. Detecting abundance trends is problematic, in part because minke whales are frequently sighted within Antarctic sea ice where navigational safety concerns prevent ships from surveying. Using icebreaker-supported helicopters, we conducted aerial surveys across a gradient of ice conditions to estimate minke whale density in the Weddell Sea. The surveys revealed substantial numbers of whales inside the sea ice. The Antarctic summer sea ice is undergoing rapid regional change in annual extent, distribution, and length of ice-covered season. These trends, along with substantial interannual variability in ice conditions, affect the proportion of whales available to be counted by traditional shipboard surveys. The strong association between whales and the dynamic, changing sea ice requires reexamination of the power to detect trends in whale abundance or predict ecosystem responses to climate change.

$\mathrm{n}$ summer, Antarctica is surrounded by a sea ice cover comprising $\sim 3-4$ million $\mathrm{km}^{2}$ of generally low concentration sea ice that forms productive and dynamic habitats for many species ${ }^{1,2}$. This ecosystem is characterized by dynamic coupling among sea ice, krill, and higher trophic level predators, including Antarctic minke whales (Balaenoptera bonaerensis) ${ }^{3,4}$. Antarctic minke whales have a circumpolar distribution in the Southern Ocean, and in the austral summer have been routinely observed in both waters adjacent to and inside the sea ice edge, where they feed predominantly on krill ${ }^{5}$. Deriving precise and unbiased estimates of abundance of cetacean species in the Antarctic region is central for understanding impacts of climate change on polar marine ecosystems, as well as for Southern Ocean ecosystem management including, specifically, the conservation and management mandate of the International Whaling Commission (IWC) ${ }^{6,7}$, particularly as this species is subject to a contentious scientific ("Special Permit”) whaling by Japan".

Under the auspices of the IWC, cetacean sightings survey data, with the primary purpose of estimating Antarctic minke whale abundance, have been collected over more than three decades in the Southern Ocean, in the open water between $60^{\circ} \mathrm{S}$ and the summer ice edge (namely, IWC's International Decades of Cetacean Research and Southern Ocean Whale and Ecosystem Research Programmes, IDCR/SOWER surveys). Each summer, vessels surveyed $30-60^{\circ}$ of longitude, completing a circumpolar survey in six or 12 years; three of such complete circumpolar surveys have been completed. These surveys represent a globally unique dataset with which to explore impact of climate change, and effects of past and present human harvest, on these marine predators. Estimates of circumpolar abundance of Antarctic minke whales in open waters between $60^{\circ} \mathrm{S}$ and the ice edge were recently derived from IDCR/SOWER sightings data9. These surveys have, however, been limited in their ability to rigorously survey areas poleward from the ice edge, because survey ships are typically insufficiently icestrengthened to survey within sea ice. The fact of minke whale presence within the marginal ice zone (MIZ) and interior sea ice pack has been known for decades ${ }^{10}$ and, therefore, IDCR/SOWER estimates from $60^{\circ} \mathrm{S}$ to the ice edge have long been recognized to be minimum estimates (i.e., negatively biased to some degree ${ }^{6}$ ). However, protocols for management decisions such as those outlined in the IWC's management schedule - which would also include judging whether the take by the contentious Japanese "scientific" whaling continues to remain at very 
small fractions of population size - work under the assumption that changes in estimates of minimum abundance over time will serve as a good proxy from which to infer population trends. However, changing ice conditions might invalidate this assumption.

Point estimates of circumpolar minimum abundance suggest a decline of $\sim 30 \%(95 \%$ CI -13, 57) from the late 1980s and throughout the following decade and a half ${ }^{9}$, but the trend is not statistically significant and large variance around these estimates makes it difficult to draw strong conclusions. At a more regional scale, statistically significant decreases in abundance have been observed around the Antarctic Peninsula and large embayments, such as the Ross and Weddell Seas, between the respective years each area was surveyed ${ }^{9}$. (Given genetic evidence for some circumpolar population structure ${ }^{9}$, there is no reason to suppose that any changes in regional abundance would occur uniformly throughout the circumpolar area.) For example, in the Weddell Sea (IWC's Management Area II; $60^{\circ} \mathrm{W}-$ $0^{\circ}$ ), the local abundance of minke whales early within the years of 1997, 1998 and 2000 (overall abundance estimate for the area derived from those years) dropped to a proportion of 0.48 (95\% CI $0.3,0.76$ ) of the abundance estimated in early 1987 (confidence interval does not consider process error) ${ }^{9}$.

A number of theories, none mutually exclusive, have been advanced to explain the difference in minke whale abundance estimates between the late 1980s and 1990s in various Southern Ocean sectors ${ }^{9}$. Perhaps in some years, in some locations, surveys either encountered or missed, by chance, higher densities of animals that were moving longitudinally. Equally, it may be that ice conditions differed from year to year and differing proportions of the total number of animals were available to be counted. Or, perhaps, the change in estimates reflects a real decline in the overall population. There is little chance to test these hypotheses retrospectively, but exploring present relationships between minke whales and sea ice can highlight potential reasons for shifts in abundance estimates and help to build more robust survey methods for the future.

To extend survey coverage further than the scope of the IDCR/ SOWER surveys, we conducted the first wide-scale surveys for cetaceans from icebreaker-supported helicopters, encompassing over $26,000 \mathrm{~km}$ of aerial survey effort, over two summers, from the German icebreaker, RV Polarstern ${ }^{11}$. Here we present the first quantitative comparison of minke whale densities in ice-covered and adjacent ice-free waters along the entire longitudinal extent of the Weddell Sea (see Methods).

\section{Results}

According to a simple model of relative abundance (i.e., not corrected for perception or availability bias) as a function of distance from the ice edge, most minke whales were found at the ice edge boundary (defined here as the 15\% ice concentration contour observed in satellite data), Fig. 1. This new information on minke whale distribution is consistent with previous reports in the Weddell Sea of larger-density patches of Antarctic krill extending $13 \mathrm{~km}$ inside the ice boundary ${ }^{12}$ that likely influence baleen whale distribution ${ }^{5}$.

A generalized additive model with a three-variable (longitude, satellite sea ice concentration and distance to the sea ice edge) tensor product smooth was selected to describe the distribution of minke whale densities across the Weddell Sea region. Our results suggest that $\sim 20 \%(95 \%$ CI 4,57$)$ of the minke whales in the Weddell Sea region could be located in the ice-covered and difficult-to-survey MIZ and further into the ice pack (based on the assumption that all animals on the trackline are seen, in both open water and inside sea ice regions; spatial distribution of predicted densities are shown in Fig. 2). There is substantial uncertainty around this point estimate, but as a starting point for discussion, our results suggest that the

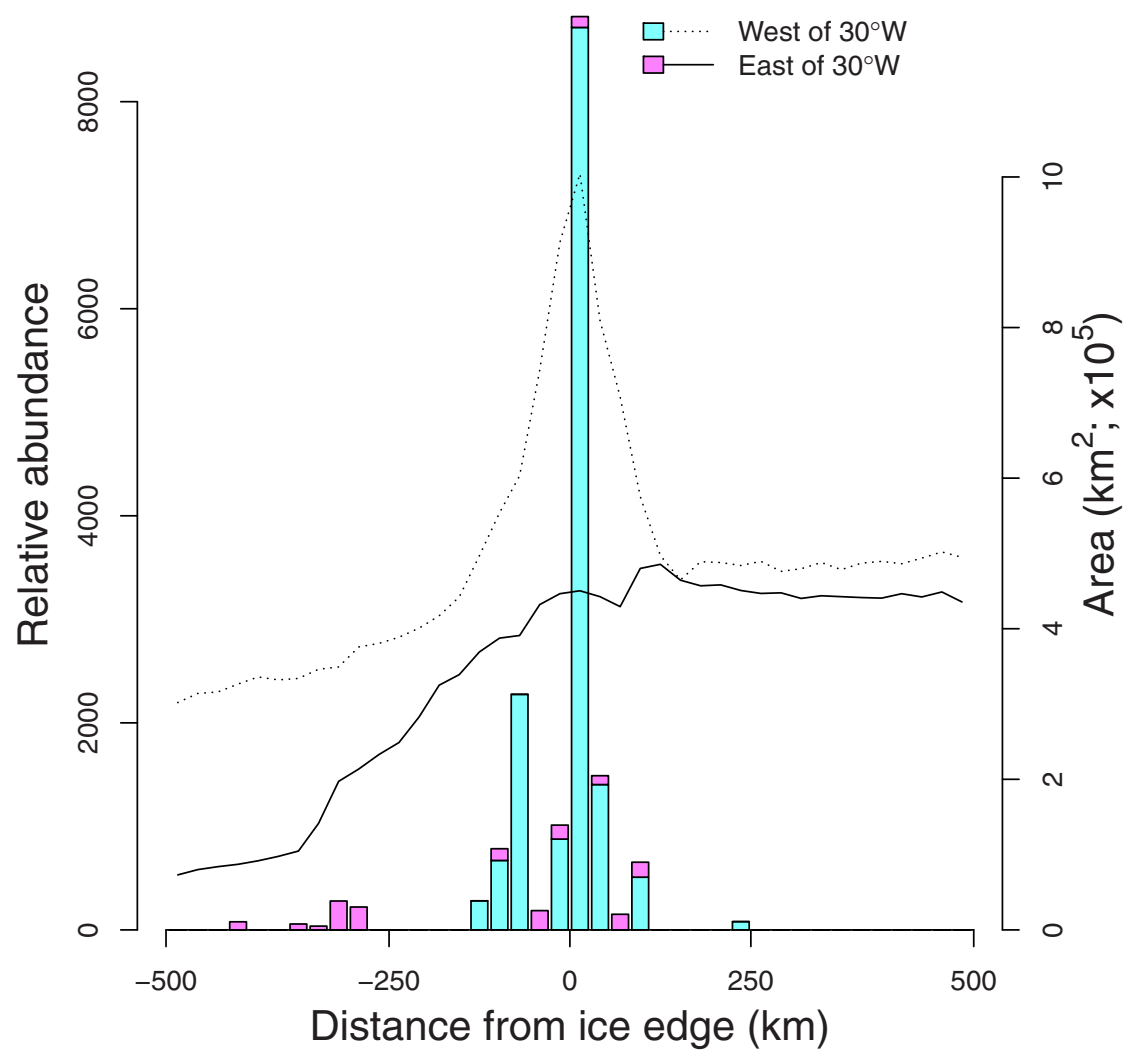

Figure 1 Relative abundance of Antarctic minke whales in $25 \mathrm{~km}$ distance bins (negative distances indicate areas inside sea ice edge) for the areas both east and west of $30^{\circ} \mathrm{W}$. Dotted and solid lines indicate the combined areas of sea ice and open water in each $25 \mathrm{~km}$ distance bin. 


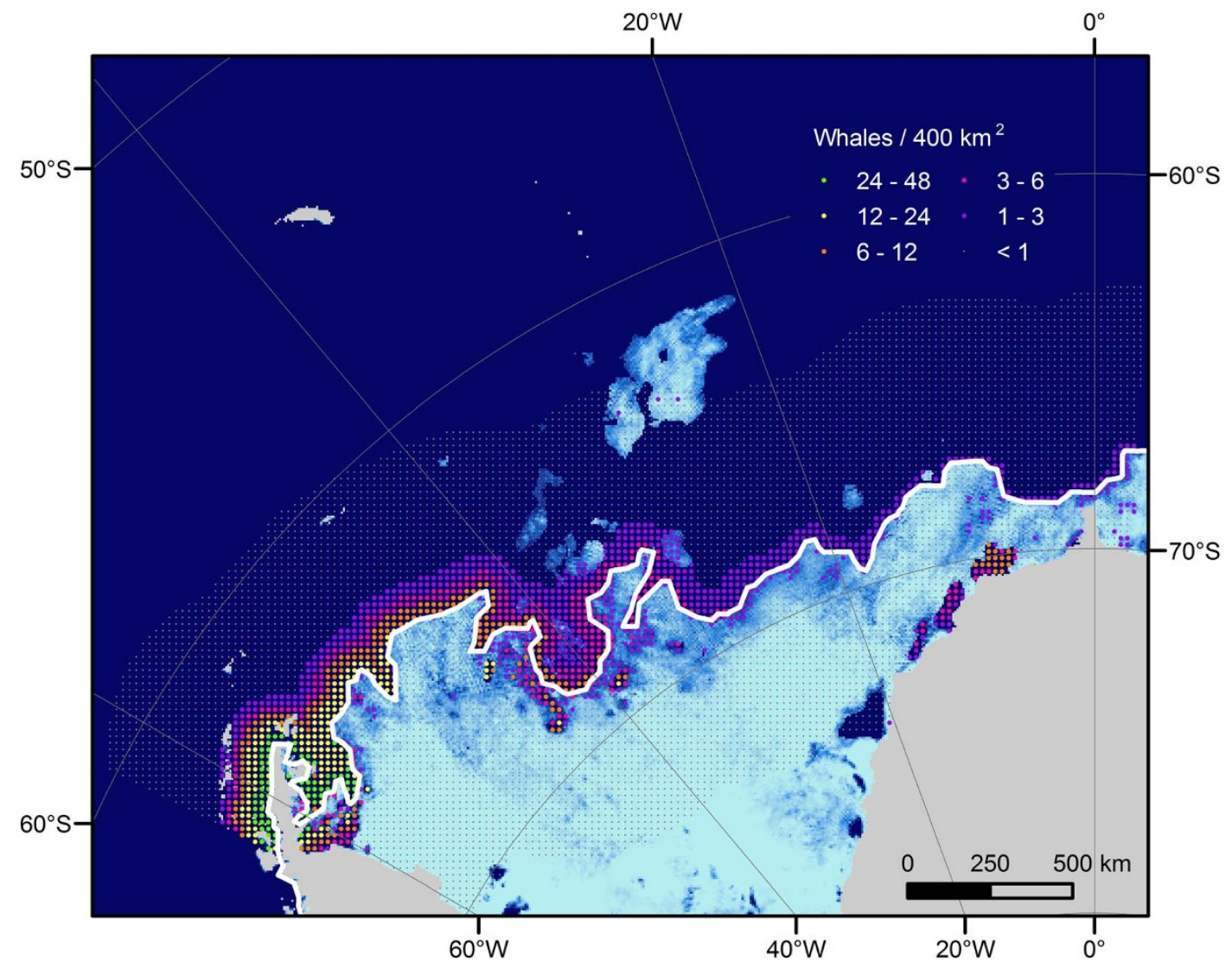

Figure $2 \mid$ Density estimates of Antarctic minke whales throughout the Weddell Sea survey region (assuming certain trackline detection probability, both inside and outside the ice). Each point estimate comprises a $400 \mathrm{~km}^{2}$ square cell. Figure was produced using package mgcv in $\mathrm{R}$ and plotted in ArcGIS 9.3.1.

proportion of whales inside the ice could be roughly half of the $\sim 50 \%$ decline in abundance between IDCR/SOWER surveys in the Weddell Sea region during the late-1980s and late 1990s'.

\section{Discussion}

The results presented in this study may inform research on summer habitat preferences and ecology of Antarctic minke whales, but here we are primarily concerned with the operational implications of their distribution and abundance on open-water surveys and any subsequent biases that might be introduced. Our icebreaker-supported helicopter surveys revealed that the proportion of Antarctic minke whales found in the difficult-to-survey sea ice zone is large, relative to the observed decline in whales between the last two circumpolar IDCR/SOWER ship surveys ${ }^{9}$. To be clear, this is certainly not to suggest that the proportion of animals estimated to be in ice alone explains the decrease in abundance in the Weddell Sea region between 1987 and a combined estimate from 1997, 1998 and 2000. There is no evidence to suggest that this species has not occupied sea ice habitats over evolutionary timescales, only to have changed that preference over the last thirty or so years. We are simply noting that the minimum number and proportion of whales in the sea ice zone are large relative to the observed decline, and cannot be considered a negligible fraction.

Using historical satellite images of the Antarctic sea ice extent, we found that the width of the MIZ (along the gradient from open water through to fast ice) might vary by as much as $50 \%$ from one year to the next in a given region (Fig. 3). Therefore, one would expect the peak in densities of minke whales near the ice edge (Fig. 1-2), inferred from aerial survey data, could be inconsistently accessible to IDCR/SOWER surveys due to intra- and inter-annual heterogeneity in sea ice conditions, and the vagaries of ice conditions could make this potential peak available or unavailable to survey. IDCR/ SOWER protocols involved stopping sighting surveys when ships slow down to navigate around ice ${ }^{6}$. Here we show that the surveys' operational threshold for navigational safety occurred precisely where whales were most likely to be found (Fig. 2).

IWC management tools only require a minimum abundance estimate and are therefore robust to surveying only a fraction of the population, but our discovery calls into question the reliability

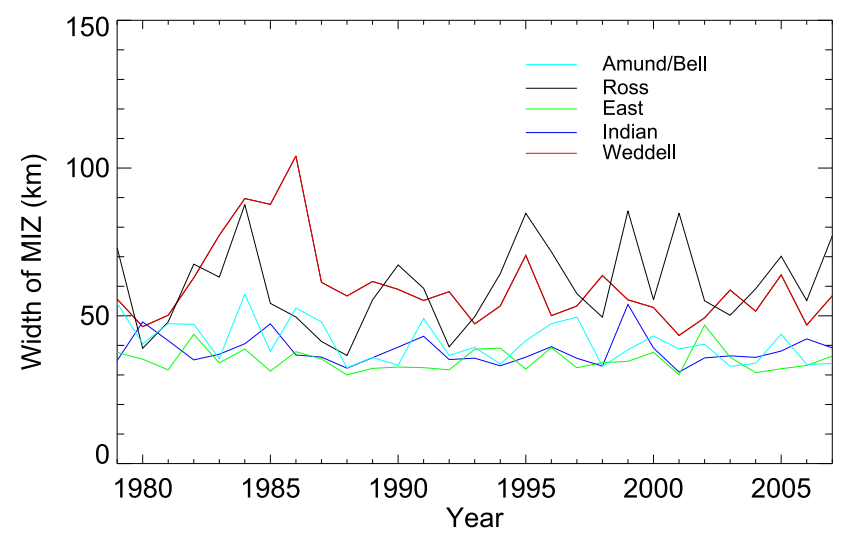

Figure $3 \mid$ The width of the, MIZ as defined by the region of very-open pack ice (0-30\% ice cover) in January for five sectors of the Southern Ocean. The width of the MIZ has experienced no or little significant trends over the past 30 years in any region. However, the variability in the width of the MIZ has a high degree of variability, such that for year to year the size of the MIZ may vary by as much as $50 \%$. Amund/Bell refers to the Amundsen and Bellingshausen Sea sector. 
of that relative abundance estimate for inferring long-term trends, either for immediate management purposes or for predicting responses of whales to a changing climate. Our findings substantiate previous anecdotal evidence of a strong affinity of minke whales with sea ice ${ }^{10}$. The coupling among minke whales, sea ice, and krill suggests that the whales are likely be sensitive to changes in ice conditions over time ${ }^{2,5}$, which could have an impact on the future of the species. Profound changes to the physical and biological oceanography have been observed in the Antarctic ${ }^{7,13}$ and these have led to complex changes to the duration and timing of sea ice season throughout the circumpolar region ${ }^{14,15}$ (Fig. 4). Our surveys and survey methodology provide a starting point for evaluating response of minke whales to changes in sea ice conditions.

Our results serve as a cautionary tale about repurposing time series data to make inferences about environmental or ecological trends in response to climate change ${ }^{16}$. As analysts worldwide are tasked with answering biodiversity and climate-related questions, repurposed time series of data may not be sufficient to the task at hand, largely because they assume, untenably, that the proportion of the population surveyed has remained constant over time. To understand climate-mediated ecological changes, we need either a series of relative abundances, in which the proportion of the population remains constant through time-a way of quantifying change in proportion sampled in relative abundance estimates-or a series of absolute abundance estimates. Here we show that generating absolute abundance estimates, i.e., that representing the entire population size, would have to include surveying the sea ice zone using icebreakersupported helicopters or using fixed-wing aircraft operating from airfields on the continent (with provision to estimate both perception and availability bias). Our results imply that detecting trends in total minke whale abundance and predicting species-level responses to changes in sea ice or other environmental drivers will be far more challenging and expensive than merely conducting circumpolar ship-board surveys in open water.

Regional-level survey data are required to be collected multiple times over the duration of a circumpolar survey to account for region-level variances in animals (i.e., process error) in order to properly interpret long-term patterns in Antarctic minke whale abundance and distribution. Given the statistical noise inherent in estimating whale abundance, it can take years or decades to detect a declining population ${ }^{17}$. Here we show that changing bias and uncertainty in existing whale population trend data could approach a similar magnitude to the suspected decline, and that existing sighting survey data may be inadequate to discriminate between true, smaller declines and shifts in distribution over various geographical and temporal scales. Our observations are timely, given that the
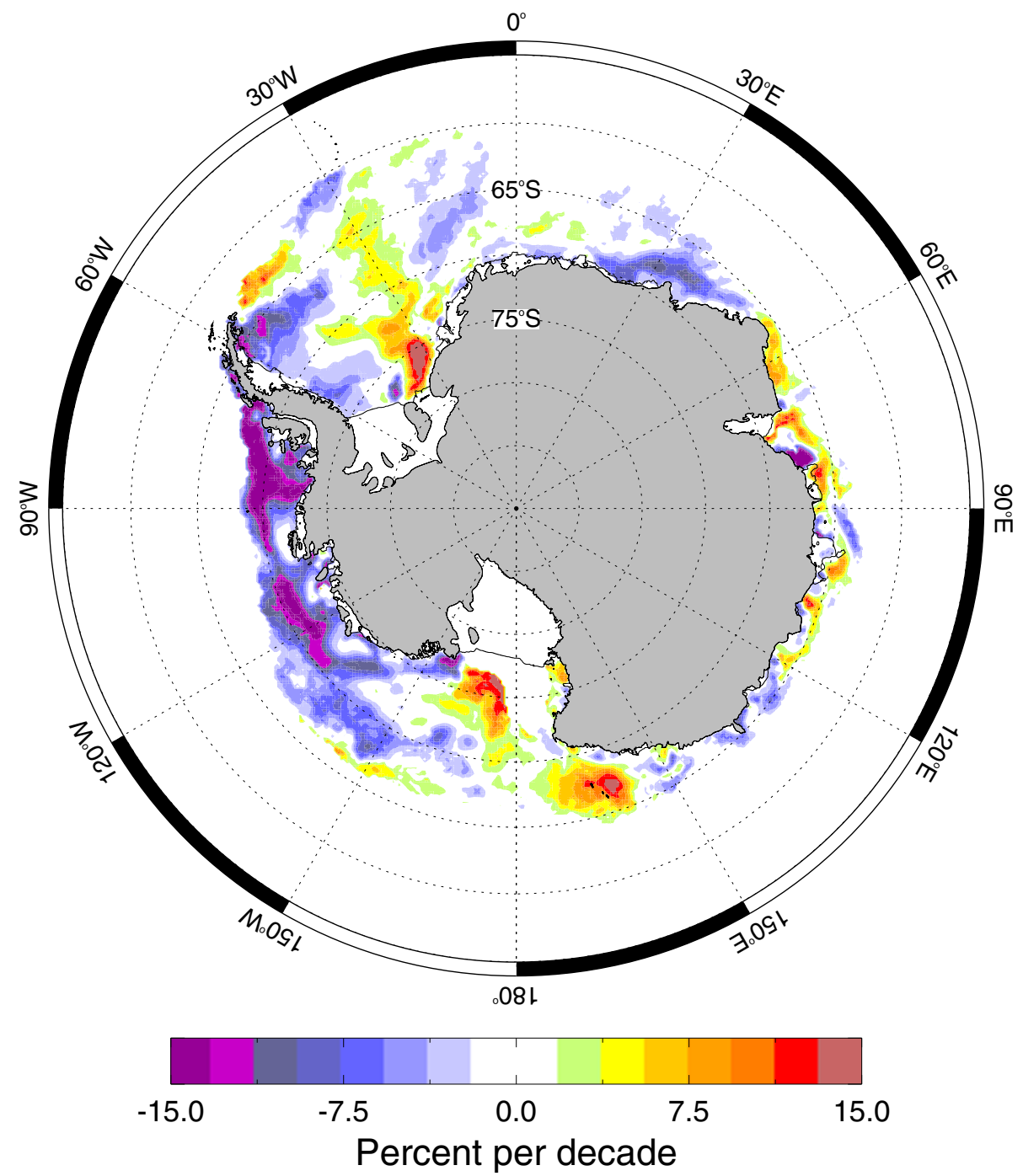

Figure $4 \mid$ Trends in average December-February sea ice concentration for 1979-2007 from satellite passive microwave data using the Bootstrap algorithm ${ }^{22}$. Large declines in summer sea ice concentration have occurred along the Antarctic Peninsula and in the Amundsen and Bellingshausen Seas, while ice concentration has increased in the western Ross Sea. Figure was produced in Interactive Data Language. 
circumpolar level results of the IDCR/SOWER surveys are now more than a decade out of date, the program has ended, and there is no plan to fund follow-on work. A definitive answer to the trends in minke whale abundance is unlikely to become available without a massive increase in funding for simultaneous ship-board surveys in open water and aerial surveys over sea ice-covered areas, while accounting for biases introduced by various diving behaviors across different sea ice habitats. Trend estimates inferred from time series of whale abundance from open-water-only surveys are unlikely to be robust to sampling non-constant proportions of the population due to climate-driven changes to sea ice. The changing physical environment of the Southern Ocean needs to be better integrated into management and conservation strategies for Antarctic minke whales, and that will involve a candid conversation about the true cost of monitoring throughout the species' range.

\section{Methods}

Field methods. Surveys were conducted from a helicopter BO-105 deployed from RV Polarstern from 1 December 2006 to 26 January 2007, and from 6 December 2008 to 3 January 2009 , and covered $26,416 \mathrm{~km}$ of trackline $\mathrm{e}^{11}$. Field protocols followed standard line transect distance sampling methodology ${ }^{18}$. Generally, the survey tracklines were planned in an ad hoc manner a few hours prior to departure, covering a rectangular shape and lasting around 2 hours. The orientation and placement of the survey design was independent of whale distribution, but was adapted depending on available flight time, changing weather and ice conditions and the course of the vessel through the ice. In some areas, the surveys were pre-designed as parallel track-lines with a random starting point following depth gradients.

Surveys were conducted at an approximate altitude of $183 \mathrm{~m}$ at a speed of $80 \mathrm{~km} / \mathrm{h}$. One or two observers were positioned in the left and right back seats of the helicopter and an additional observer sat in the front left seat of the helicopter and observed the area ahead, focusing on the transect line. The helicopter's position was stored every 4 seconds. Information on sea state (Beaufort Sea state scale), cloud cover (in octaves), glare (strength and area affected), ice coverage (in percent) and overall sighting conditions (good, moderate, poor) was recorded at the beginning of each survey and whenever conditions changed. Ice coverage was averaged for a search area $1 \mathrm{~km}$ in front of the helicopter, assessed by the front observer. For each cetacean sighting the following data was recorded: location, distance to trackline, species, group size, group composition, behavior, cue, swimming direction and reaction to the helicopter.

Ice covariate data. Ice concentration observed along the trackline was recorded by the observers aboard the helicopter. Distance (in $\mathrm{km}$ ) to the marginal ice edge was derived post hoc from the data using satellite remote sensing from daily, $6.25 \mathrm{~km}$ resolution ice concentration images collected by the Advanced Microwave Scanning Radiometer for EOS (AMSR-E) satellite sensor and published by the Institute of Environmental Physics, University of Bremen ${ }^{19}$. The observer-derived estimate for ice concentration was tested in subsequent distance analyses.

The ice edge was defined for each day that transects were flown by the smooth line inscribing the $15 \%$ ice concentration margin, which is a standard definition in studies of sea ice ${ }^{20}$. The position of the ice edge was then estimated in each satellite image using ArcGIS 9.3.1 Spatial Analyst functions (Environmental Systems Research Institute, Inc, Redlands, California, 2009) by selecting the largest polygon of contiguous water pixels having at least $15 \%$ ice concentration (i.e. the polygon encom passing the land-fast ice), extracting the outermost edge, and smoothing it using the Spatial Analyst "Boundary Clean" operator with the default parameters. Finally, the Marine Geospatial Ecology Tools software ${ }^{21}$ was used to match whale sightings and survey segments to satellite images and calculate the distance to the closest ice edge for each sighting and survey segment midpoint (see below for a description of the survey segments).

Changes in sea ice concentration over last 40 years. We examined spatio-temporal variability of sea ice since 1979 in two ways. First, we plotted the size of the MIZ throughout the Antarctic since 1979 from satellite passive microwave sea ice concentration estimates ${ }^{22}$. We examined the data for evidence of decadal-scale changes in the region between 5 and 30\% ice concentration (i.e., in the vicinity of the ice edge, where minke whales are found but that are difficult to survey using conventional ship-board surveys). We acknowledge that such a definition is arbitrary, but for our purposes, it provides a useful measure of the variability of the MIZ. Determining the size of the MIZ is problematic with passive microwave data as ice concentration is often underestimated in summer and low concentrations near the ice edge are not deemed particularly reliable ${ }^{23}$. Hence, the ice edge is most often defined as the $15 \%$ concentration contour. We used February monthly average ice concentration data determined using the bootstrap algorithm available from the National Snow and Ice Data Center ${ }^{24}$. The second way we considered changes in sea ice patterns was to plot changes in ice concentration, using methods described in previous assessments ${ }^{15}$, but restricting inference to the season (Dec 15-Feb 15) in which IWC whale surveys take place.
Statistical analysis of minke whale and sea ice data. The distribution of different densities of Antarctic minke whales around the sea ice edge in the study area was estimated from line transect data following conventional distance sampling approaches $^{18}$. Due to small sample sizes, line transect data from both survey years were pooled for distance analysis ( $n=62$ in 2006/07, $n=32$ in 2008/09). Sightings that were judged to be either minke $(n=82)$ or 'like' minke whale $(n=2)$ were included in the analysis. Although there may be differences in both the ability of observers to see minke whales on the trackline across various concentrations and types of sea ice (i.e., perception bias) or the diving behaviour of whales in various ice habitats (i.e., availability bias), such information is currently unavailable. (It is hoped recent advances in satellite and depth-recording tags deployed on Antarctic minke whales may help inform on availability bias for future analyses ${ }^{25}$. Therefore, as the survey was single-platform, the probability of detection on the trackline, i.e., $g(0)$, was assumed to be 1 for the entire survey region, with a half-normal detection function. Environmental covariates (i.e., multiple covariate distance sampling, MCDS ${ }^{18}$ ), such as sighting conditions and observer judged sea ice concentrations, were tested and found not to contribute to the distance analysis (judged using AIC).

Each transect was split into segments of approximately 30 nautical miles in length to minimise spatial autocorrelation (assumption tested by checking residuals) ${ }^{26}$. An effective strip half width (assumed to be doubled when observers were present on both sides of the aircraft) was estimated from the detection function for each transect segment; whale densities were calculated based on the number of animals counted in each segment and the effective strip area (i.e., segment length $\times$ the effect strip width).

A simple estimate of the relative abundance of minke whales, as a function of distance from the ice edge, up to $500 \mathrm{~km}$, was derived from segment-level density estimates and the position of the sea ice boundary on the day each segment was flown. The distance from the centre of each transect segment to the sea ice boundary was allocated to $25 \mathrm{~km}$ bins. Negative distances refer to areas inside of ice boundary. A mean relative density was estimated from segments in each $25 \mathrm{~km}$ bin, weighted by the summed effective strip area. The total area of ice and water within each binned distance range was estimated using AMSR-E sea ice data for January 12007 (nominated as a representative day for the two years of surveys). The relative abundance of animals in each distance bin was then estimated by multiplying area in each bin by mean relative density. Given the error involved in locating that actual sea ice boundary using satellite data, we tested the sensitivity of this result to differing distances to the putative sea ice boundary; the 'peak' in density of minke whales near the supposed sea ice boundary was robust to up to $100 \mathrm{~km}$ of random noise added to the distances to this feature (larger amounts of noise were not tested).

A model-based approach ${ }^{27}$ was used to predict for the densities of minke whales across the Weddell Sea region, up to $500 \mathrm{~km}$ on either side of the ice edge. This is a common approach to estimate densities and abundances when track designs deviate substantially from ideal design-based principles. Densities were modelled using a generalized additive model (GAM) using the mgcv library ${ }^{28}$ in $\mathrm{R}$ ( $\mathrm{R}$ Core Development Team, R Foundation for Statistical Computing, Vienna), in particular, a tensor product smooth with three variables, namely longitude, the great circle distance to the ice edge and a satellite-derived estimate of ice concentration, with sea ice data from each day the effort was undertaken. Model selection was via REML, and overdispersion in sighting counts was accounted for with the Tweedie distribution ${ }^{26}$ Density predictions were made at the scale of the sea ice data $(6.25 \mathrm{~km}$ grid); variance of abundance generated using the spatial model was estimated using methods described previously ${ }^{26}$. Given whale densities predicted by the GAM for each grid point, and the size of the study area (i.e., the prediction grid shown in Fig. 2), we estimate abundance of 2500 minkes $(C V=0.90)$ inside the sea ice zone and 8500 minkes $(\mathrm{CV}=0.56)$ in adjacent, ice-free waters, given no additional information on availability or perception bias in either region. Assuming no difference in either perception or availability bias with sea ice concentration (or any other unmodelled covariate), this implies that $\sim 20 \%$ ( $95 \%$ CI 4, 57; interval derived using bootstrap) of the Antarctic minke whales we estimated to be found in our study area were distributed inside of the sea ice zone in the Weddell Sea region.

1. Thomas, D. N. \& Dieckmann, G. S. Ocean science - Antarctic Sea ice - a habitat for extremophites. Science 295, 641-644 (2002).

2. Nicol, S., Worby, A. \& Leaper, R. Changes in the Antarctic sea ice ecosystem potential effects on krill and baleen whales. Mar. Freshwater Res. 59, 361-382 (2008).

3. Nicol, S. et al. Ocean circulation off east Antarctica affects ecosystem structure and sea-ice extent. Nature 406, 504-507 (2000).

4. Loeb, V.et al. Effects of sea-ice extent and krill or salp dominance on the Antarctic food web. Nature 387, 897-900 (1997).

5. Friedlaender, A. S. et al. Whale distribution in relation to prey abundance and oceanographic processes in shelf waters of the Western Antarctic Peninsula. Mar. Ecol. Prog. Ser. 317, 297-310 (2006).

6. Branch, T. A. \& Butterworth, D. S. Southern hemisphere minke whales: Standardised abundance estimates from the 1978/79 to 1997/98 IDCR-SOWER surveys. J. Cetacean Res. Manage. 3, 143-174 (2001)

7. Schofield, O. et al. How Do Polar Marine Ecosystems Respond to Rapid Climate Change? Science 328, 1520-1523 (2010).

8. Gales, N. J., Kasuya, T., Clapham, P. J. \& Brownell, R. L. Japan's whaling plan under scrutiny. Nature 435, 883-884 (2005).

9. International Whaling Commission. Annual Report of the Scientific Committee. (International Whaling Commission, Panama, 2012). 
10. Laws, R. M. Seals and whales of the southern ocean. Philos. T. Roy. Soc. B 279, 81-96 (1977).

11. Scheidat, M. et al. Cetacean surveys in the Southern Ocean using icebreakersupported helicopters. Polar Biol. 34, 1513-1522 (2011).

12. Brierley, A. S. et al. Antarctic krill under sea ice: Elevated abundance in a narrow band just south of ice edge. Science 295, 1890-1892 (2002).

13. Stammerjohn, S. E., Martinson, D. G., Smith, R. C., Yuan, X. \& Rind, D. Trends in Antarctic annual sea ice retreat and advance and their relation to El NiñoSouthern Oscillation and Southern Annular Mode variability. J. Geophys. Res. 113, C03S90, doi:10.1029/2007jc004269 (2008).

14. Massom, R. et al. Change and Variability in East Antarctic Sea Ice Seasonality, 1979/80-2009/10. PLoS ONE 8, e64756 (2013).

15. Stammerjohn, S., Massom, R., Rind, D. \& Martinson, D. Regions of rapid sea ice change: An inter-hemispheric seasonal comparison. Geophys. Res. Lett. 39, L06501, doi:10.1029/2012gl050874 (2012).

16. Walther, G.-R. et al. Ecological responses to recent climate change. Nature 416, 389-395 (2002).

17. Taylor, B. L., Martinez, M., Gerrodette, T., Barlow, J. \& Hrovat, Y. N. Lessons from monitoring trends in abundance of marine mammals. Mar. Mammal Sci. 23, 157-175 (2007).

18. Buckland, S. T. et al. Introduction to Distance Sampling: estimating abundance of biological populations. (Oxford University Press, 2001).

19. Spreen, G., Kaleschke, L. \& Heygster, G. Sea ice remote sensing using AMSR-E 89GHz channels. J. Geophys. Res. 113, C02S03, doi:10.1029/2005jc003384 (2008).

20. Rott, H., Nagler, T. \& Skvarca, P. Rapid collapse of northern Larsen Ice Shelf, Antarctica. Science 271, 788-792 (1996).

21. Roberts, J. J., Best, B. D., Dunn, D. C., Treml, E. A. \& Halpin, P. N. Marine Geospatial Ecology Tools: An integrated framework for ecological geoprocessing with ArcGIS, Python, R, MATLAB, and C++. Environ. Modell. Softw. 25, 1197-1207 (2010).

22. Comiso, J. C. \& Nishio, F. Trends in the sea ice cover using enhanced and compatible AMSR-E, SSM/I, and SMMR data. J. Geophys. Res. 113, C02S07 (2008).

23. Worby, A. P. \& Comiso, J. C. Studies of the Antarctic sea ice edge and ice extent from satellite and ship observations. Remote Sens. Environ. 92, 98-111 (2004).

24. Comiso, J. Bootstrap Sea Ice Concentrations from Nimbus-7 SMMR and DMSP SSM/I-SSMIS, Version 2; NASA DAAC database. (National Snow and Ice Data Center, 2012).

25. Friedlaender, A. S. et al. Feeding rates and under-ice foraging strategies of the smallest bulk-filter feeder, the Antarctic minke whale. Biol. Lett. (Accepted).

26. Williams, R. et al. Chilean Blue Whales as a Case Study to Illustrate Methods to Estimate Abundance and Evaluate Conservation Status of Rare Species. Conserv. Biol. 25, 526-535 (2011).

27. Hedley, S. \& Buckland, S. Spatial models for line transect sampling. J. Agric. Biol. Enviro. S. 9, 181-199 (2004).

28. Wood, S. Generalized Additive Models: An Introduction with R. (Taylor \& Francis, 2006).

\section{Acknowledgments}

The authors thank the crew, the meteorological team and especially the helicopter crew on board of the RV Polarstern for their professional work. We thank Stefan Bräger, Kristina Lehnert and Hans Verdaat for their observer work and Gunnar Spreen and his colleagues for providing AMSR-E ice concentration data. The data presented here are archived with AWI. We thank David Peel, Mark Bravington and Mike Double for helpful feedback on previous versions of this manuscript, and Alana Phillips for editing and formatting of the final manuscript. This work received funding from the following institutions: Alfred Wegener Institute for Polar and Marine Research (AWI); Dutch Ministry of Agriculture, Nature and Food Quality (EL \& I); German Federal Ministry of Food, Agriculture and Consumer Protection (BMELV); German Federal Ministry for the Environment, Nature Conservation and Nuclear Safety (BMU); the Institute for Marine Resources and Ecosystem Studies (Wageningen IMARES); Johann Heinrich von Thünen Institute (Federal Research Institute for Rural Areas, Forestry and Fisheries); the Netherlands Polar Programme (NPP) of the Netherlands Organisation for Scientific Research (NOW); Research and Technology Centre Westcoast (FTZ) of the University Kiel. RW was funded by a Marie Curie International Incoming Fellowship within the 7th European Community Framework Programme (proposal N 253407 (call reference: FP7- PEOPLE-2009-IIF).

\section{Author contributions}

Designed the study: O.B., K.H.K., M.S., U.S. and R.W. Collected the data: O.B., H.F.H., K.H.K., L.S.L., M.S. and R.W. Analysed the data: N.K., T.M., J.R., M.S. and R.W. Wrote the paper: A.S.B., A.S.F., N.K., T.M., J.R., M.S. and R.W. Prepared the figures: N.K. (Figs 1 and 2), T.M. (Figs 3 and 4) and J.R. (Fig 2). All authors reviewed the manuscript.

\section{Additional information}

Competing financial interests: The authors declare no competing financial interests. How to cite this article: Williams, R. et al. Counting whales in a challenging, changing environment. Sci. Rep. 4, 4170; DOI:10.1038/srep04170 (2014).

This work is licensed under a Creative Commons AttributionNonCommercial-NoDerivs 3.0 Unported license. To view a copy of this license, visit http://creativecommons.org/licenses/by-nc-nd/3.0 